\title{
O Perfil Motivacional dos Colaboradores de uma Vara Federal do Município de Juazeiro do Norte - CE \\ Francisca Valdilene Fernandes Barbosa ${ }^{1}$; José Leandro de Almeida Neto ${ }^{2}$
}

\begin{abstract}
Resumo O presente artigo faz uma abordagem acerca da motivação dos colaboradores de uma Vara Federal do município de Juazeiro do Norte/CE. Com o objetivo de investigar os fatores capazes de motivar esses colaboradores, são consideradas importantes teorias a exemplo da hierarquia das necessidades, dos fatores higiênicos e das necessidades socialmente adquiridas. Sobre mecanismos capazes de impulsionar motivação são destacados aspectos relacionados ao ciclo motivacional, além das interferências da motivação no ambiente de trabalho, tais como o reconhecimento e a cooperação entre os colaboradores. Essas teorias servem de base para a compreensão de fatores capazes de gerar motivação. A necessidade de conhecer o perfil motivacional dos servidores envolvidos no desempenho de atividades no âmbito do poder judiciário federal justifica a elaboração deste trabalho. Após pesquisa bibliográfica, é apresentado, de forma criteriosa, um estudo de caso acerca do tema. Trata-se de uma pesquisa aplicada a 18 (dezoito) colaboradores de uma Vara Federal, permitindo uma análise quantitativa dos resultados. A partir dos dados coletados, observou-se que a comunicação foi apontada como importante fator motivacional por mais de $88 \%$ dos servidores daquela Vara Federal. O resultado do questionário mostrou a importância de conhecer os fatores motivacionais, de modo a contribuir para uma administração pautada pela excelência em gestão de pessoas.
\end{abstract}

Palavras-chave: Motivação. Colaboradores. Satisfação.

\section{The Motivational Profile of employees of a Federal Court in Juazeiro do Norte-CE}

\begin{abstract}
This article aims to present an approach on the level of motivation of employees of a Federal Court in Juazeiro do Norte/CE, taking into consideration important theories such as the hierarchy of needs, hygiene factors and the socially acquired necessities. These theories are the basis for understanding the factors that are capable of generating motivation. On mechanisms to boost motivation, aspects related to the role of the motivational cycle are highlighted, besides interferences of motivation in the workplace, such as recognition and co-operation among employees. The need to know the servers' profile involved in the performance motivational of activities within the reach of Federal Judicial Power justifies this study. After bibliographical research, a case study on the topic is, carefully, presented. It consists of a research applied to 18 (eighteen) employees of a Federal Court, allowing quantitative analysis of the results. From the collected data it was observed that communication was identified as an important motivational factor for over $88 \%$ of the servers of that Federal Court. The result of the questionnaire has shown the importance of knowing the motivational factors in order to contribute to an administration guided by excellence in people management.
\end{abstract}

Keywords: Motivation. Employees. Satisfaction.

\section{Introdução}

O desenvolvimento de grandes corporações impôs ao mundo globalizado novas necessidades na área de gestão de pessoas. Preocupados com essa problemática, muitos estudiosos passaram a se dedicar ao estudo de fatores relacionados à motivação no ambiente de trabalho. A busca pela manutenção de colaboradores motivados ganhou lugar especial nesse novo cenário criado a partir do surgimento das grandes instituições ou corporações.

\footnotetext{
${ }^{1}$ Graduada em Odontologia; pós-graduanda em Gestão de Recursos Humanos; e-mail: valdilenefb@oi.com.br

${ }^{2}$ Professor Especialista, Mestrando em Ciências da Educação, da Faculdade de Ciências Aplicadas Dr. Leão Sampaio. E-mail: leandro@leaosampaio.edu.br.
} 
Nesse contexto, a motivação é fator preponderante para o sucesso das atividades desenvolvidas. Ela impulsiona pessoas a trabalharem de forma satisfatória, comprometidas com os resultados que a instituição se propõe a alcançar. A ausência de motivação, a contrário senso, é capaz de comprometer todo o resultado do trabalho, com repercussões negativas para a produtividade e para a relação interpessoal. Assim, os novos tempos apontam para a necessidade de gestores comprometidos com a motivação de seus colaboradores.

Com efeito, a presente pesquisa tem como objetivo geral conhecer o perfil motivacional dos colaboradores de uma Vara Federal do município de Juazeiro do Norte-Ceará. Para tanto, se preocupou em estudar os principais fatores que auxiliam ou mesmo determinam a motivação e o consequente grau de satisfação dos indivíduos em seu ambiente de trabalho, bem como verificar se o volume de tarefas influencia na motivação dos colaboradores.

A elaboração dessa pesquisa se justifica pela premente necessidade de se conhecer o perfil motivacional dos colaboradores envolvidos no desempenho de atividades no âmbito do poder judiciário federal, notadamente no município de Juazeiro do Norte-Ceará, com vistas ao aprimoramento da relação servidor-usuário, bem como do trabalho oferecido ao jurisdicionado.

Este trabalho tem como base uma pesquisa bibliográfica de caráter descritivo, exploratório, em que se realizou um estudo de caso, por meio de questionário objetivo e estruturado. Os dados consolidados mostraram que mais de $88 \%$ dos servidores apontaram a importância da comunicação para a motivação no ambiente de trabalho.

Destarte, a obtenção e análise dos resultados têm papel fundamental para proporcionar a criação de ferramentas de conhecimento para as organizações e para a comunidade acadêmica.

\section{Conceito de Motivação}

Segundo Bergamini (2002), a verdadeira motivação nasce a partir de necessidades interiores e não de fatores externos. Não há fórmulas que ofereçam soluções fáceis para motivar as pessoas. A palavra motivação tem origem na palavra latina movere, que significa, em última análise, mover. Com efeito, a motivação está atrelada à ideia de dinâmica ou de ação que é a principal base dessa importante função da vida psíquica.

A motivação possui caráter intrínseco, pois se origina de necessidades interiores, cabendo aos gestores estimular, incentivar e provocar a motivação de seus colaboradores (VERGARA, 2007).

Os motivos que levam uma pessoa a estar motivado frente a suas atribuições são de ordem tangível, a exemplo do dinheiro, e intangível, a exemplo da própria realização pessoal. Assim, pode-se constatar que as razões motivacionais são diferentes para cada pessoa, e que a manutenção de uma 
organização com um número considerável de membros, conquanto estejam todos motivados, não constitui tarefa fácil (LOPES, 2003).

Ribeiro (2006, p. 36) afirma que a "motivação pode ser caracterizada da seguinte maneira: aquilo que é capaz de levar alguém à determinada forma de comportamento”. Dessa ideia depreendese que a motivação é uma força capaz de impulsionar pessoas a buscar seus ideais.

A respeito do conceito ora apresentado, acrescenta-se:

Motivação é a força que nos estimula a agir provocando algum tipo de ação ou comportamento humano, (...) a motivação indica um processo pelo qual um conjunto de razões ou motivos explica, induz, incentiva, estimula ou provoca algum tipo de ação ou comportamento humano motivado. (LOPES, 2003, p. 08).

De acordo com Marras (2011), os indivíduos apesentam um rol de necessidades, com peculiaridades e intensidades próprias e diversas. Assim, eles estão constantemente buscando contemplar essas necessidades, com vistas à satisfação. A motivação é a força propulsora que impulsiona pessoas ao encontro da pretendida satisfação. $\mathrm{O}$ autor ressalta, oportunamente, que a motivação vem despertando a atenção de estudiosos e cientistas, sobretudo a partir do início do século XX, período em que se tem registro de estudos inaugurais na área de motivação.

Acerca da importância de se estudar a motivação, observa-se:

É oportuno que o estudo do fenômeno motivacional não objetiva apenas, dentro de uma ótica instrumental, obter mais funcionários. Acreditamos que, sob um enfoque humanista, uma compreensão profunda da dinâmica dos indivíduos permite atuarem de forma consciente, buscando uma interseção entre os mais legítimos interesses de cada membro do corpo funcional e as demandas da organização e da sociedade. (CAVALCANTI, 2009, p. 86).

Essa preocupação em desenvolver um ambiente de trabalho sadio onde cada membro da organização opere de maneira satisfatória tornou-se, ao longo dos anos, pedra de toque das empresas. Dessa preocupação, surgiram vários estudos na busca de compreender que fatores contribuem para a motivação do funcionário.

\section{Teorias Motivacionais}

Sobre a motivação foram desenvolvidas várias teorias, dentre as quais podem ser destacadas três das mais importantes: a Teoria da hierarquia de necessidade de Maslow, a Teoria das necessidades socialmente adquiridas de McClelland e a Teoria da motivação-higiene de Herzberg. 
Chiavenato (2009) registra que Maslow hierarquizou as necessidades que motivam as pessoas em cinco grupos: necessidades fisiológicas, necessidades de segurança, necessidades sociais, necessidades de estima e, por fim, necessidades de auto-realização. Os indivíduos iniciam o processo de motivação a partir das necessidades vitais e vão subindo numa escala até chegar ao topo da pirâmide, traduzida pelas necessidades de auto-realização. Isso implica que o indivíduo sempre tem algo que o impele a estar motivado, uma vez que satisfeita uma necessidade ele parte em busca de um novo desafio.

Cavalcanti (2009) informa que as necessidades constantes no nível basilar da pirâmide são determinantes no comportamento dos indivíduos, enfatizando que quando satisfeitas tais necessidades, estas deixam de gerar motivação. Sobre isso verifica-se:

A existência de hierarquia nas necessidades humanas como premissa básica da teoria de Maslow explica-se da seguinte forma: os indivíduos possuem necessidades distintas de acordo com uma série de variáveis intrínsecas ou extrínsecas (...) e somente passam a buscar satisfação de uma necessidade de nível superior quando a imediatamente inferior já estiver satisfeita de modo pleno. (MARRAS, 2011, p. 26).

Essas necessidades são o que dão impulso ao ser humano para buscar motivação. São elas que levam o indivíduo a superar obstáculos e a procurar novos estímulos.

É apresentada a seguir a pirâmide que caracteriza a sequência das necessidades a serem atendidas.

Figura 01: Pirâmide de necessidades de Maslow.

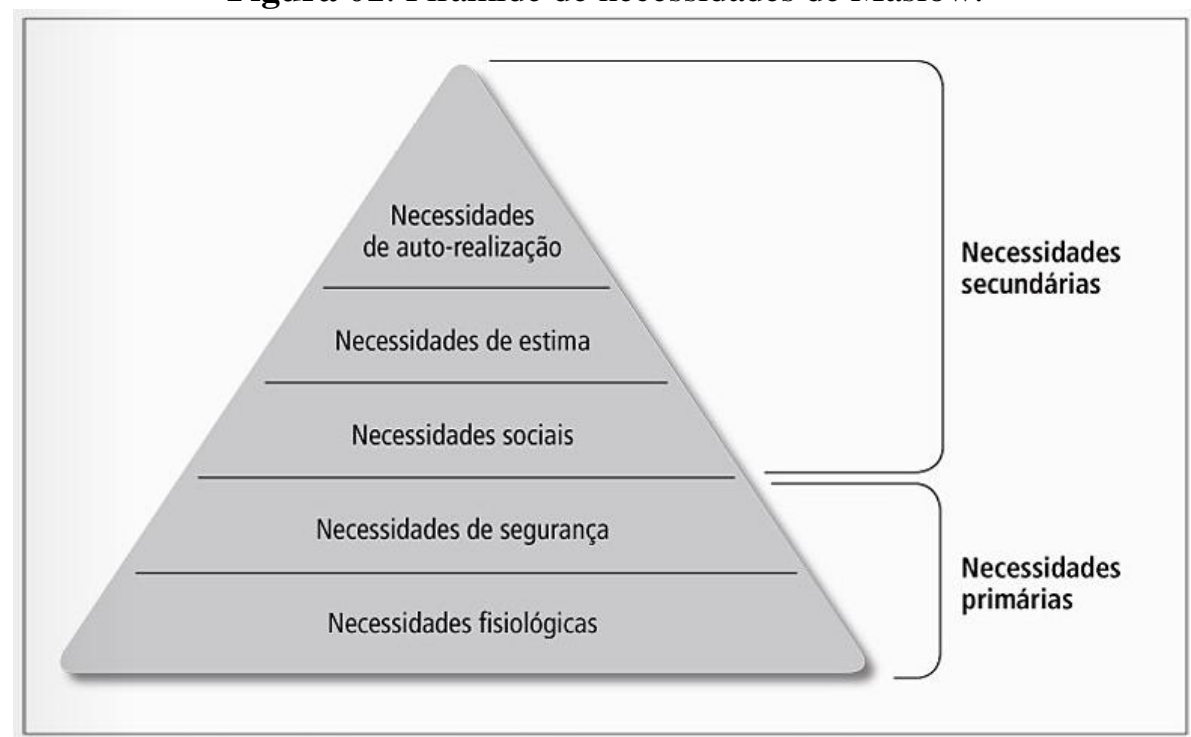

Fonte: Chiavenato (2009, p. 125). 
À proporção que as atividades do dia a dia são realizadas e trazem satisfação, as habilidades são desenvolvidas de forma compensatória, fazendo com que se busquem novos desafios.

McClelland identificou três tipos de necessidades que impulsionam os indivíduos em sua busca pela motivação: realização, afiliação e poder. A realização é entendida como a necessidade de atingir objetivos e de superar obstáculos; a afiliação diz respeito à capacidade de se relacionar em sociedade; e o poder se refere à capacidade de influenciar pessoas e gerenciar situações (CAVALCANTI et al., 2009).

Sobre a Teoria dos dois fatores, Herzberg identificou fatores motivacionais ou satisfacientes, capazes de gerar satisfação e fatores higiênicos. Os fatores motivacionais proporcionam satisfação com o cargo e com as possíveis melhorias relacionadas ao desempenho, relacionando-se com as necessidades mais elevadas da hierarquia de Maslow, tais como: realização, reconhecimento, responsabilidade, crescimento e trabalho em si. Já os fatores higiênicos, também denominados insatisfacientes, não proporcionam motivação, mas quando precários, impedem a satisfação no trabalho. Assim, os fatores higiênicos são aqueles externos à atividade, abrangendo condições de trabalho e conforto pessoal, políticas da empresa e administração, salários e benefícios sociais, status, relacionamento com o supervisor, competência técnica do supervisor, segurança no cargo e relacionamentos interpessoais (CHIAVENATO, 2009).

A esse respeito, verifica-se:

É difícil algum funcionário manter sempre o mesmo nível de motivação ao longo de sua carreira na mesma empresa, quando esta não dá condições de satisfazer as necessidades de auto-realização, ou seja, quando o trabalho se torna uma monotonia (LOPES, 2003, p. 26).

As organizações que visam a funcionários motivados precisam dar condições para que estes tenham orgulho de participar daquele grupo organizacional. É indispensável criar um ambiente de confiança e lealdade entre os membros.

Tais teorias são de grande importância na busca por colaboradores motivados, pois elas explicam de diferentes modos os fatores que interferem no melhor comportamento dos membros nas empresas.

Manter-se motivado para o trabalho é um desafio e, ao mesmo tempo, um caminho viável para alcançar resultados satisfatórios. O profissional motivado traz vantagens para si, para o grupo.

Partindo desse princípio é preciso entender e valorizar os motivos que levam o profissional a se manter motivado, a fim de se obter um bom desempenho na corporação. 


\section{Ciclo Motivacional}

Após a elaboração de um breve conceito sobre motivação e a explicação de três de suas mais importantes teorias, faz-se mister realizar uma sucinta abordagem no que concerne ao ciclo motivacional.

Segundo Chiavenato (2009), o processo se inicia com uma necessidade do indivíduo, que na pirâmide de Maslow se origina com as necessidades básicas como alimentação, por exemplo. A necessidade é o motivo da ação. Ela é provocada por um desequilíbrio devido a carências ou privações. O desequilíbrio provoca um estado de tensão, um desconforto que obriga o indivíduo a realizar um tipo de comportamento, em busca de solucionar o desconforto criado a partir da necessidade primeira. Satisfeita tal necessidade, o indivíduo entra em um estado de satisfação que o leva a um equilíbrio. Este equilíbrio perdura até que surja outra necessidade decorrente de um novo estímulo, e então se inicia todo o ciclo novamente.

Para Whitmore (2012, p. 138), "as pessoas procuram se engajar em atividades que ajudam a satisfazer suas necessidades, estando apenas parcialmente conscientes desse processo".

Ainda de acordo com Chiavenato (2009), em alguns casos, o ciclo processual não se completa, pois nem sempre as necessidades são satisfeitas. Isso ocorre no momento da tensão, que pode ser satisfeita, frustrada ou mesmo compensada. Quando a tensão é satisfeita ocorre o ciclo de forma completa. Entretanto, nos casos em que ela é frustrada, o ciclo não se fecha, desenvolvendo-se, no organismo humano, diversas reações, notadamente emocionais e psíquicas. Em outros casos, há a possibilidade de uma compensação, ou seja, o indivíduo procura outras formas de realizar a satisfação através de outras necessidades. Isso é uma forma de minimizar as reações desencadeadas no organismo em virtude da não satisfação das necessidades. Sobre tal assunto ressalta-se:

O Ciclo Motivacional pode alcançar vários níveis de resolução da tensão: uma necessidade pode ser satisfeita, frustrada (...) ou compensada (...). Muitas vezes a tensão provocada pelo surgimento da necessidade encontra uma barreira ou obstáculo para sua liberação. Não encontrando a saída normal, a tensão represada no organismo procura um meio indireto de saída, seja pela via psicológica (...), seja por via fisiológica (...). Outras vezes, a necessidade não é satisfeita nem frustrada, mas é transferida ou compensada. Isso de dá quando a satisfação de outra necessidade reduz ou aplaca a intensidade de uma necessidade que não pode ser satisfeita (CHIAVENATO, 2009, p. 124).

A partir dos ensinamentos de Kwasnicka (2009), verifica-se que os indivíduos raramente conseguem chegar ao nível de completa satisfação, exceto por determinado espaço de tempo. No momento em que um objetivo é satisfeito, outro aparece em seu lugar, e quando atendido, outro o substitui. As necessidades ordenadas funcionam como verdadeiros fatores de motivação para o homem. Observe a figura a seguir, que ilustra as etapas do ciclo motivacional. 
Figura 02: Ciclo Motivacional.

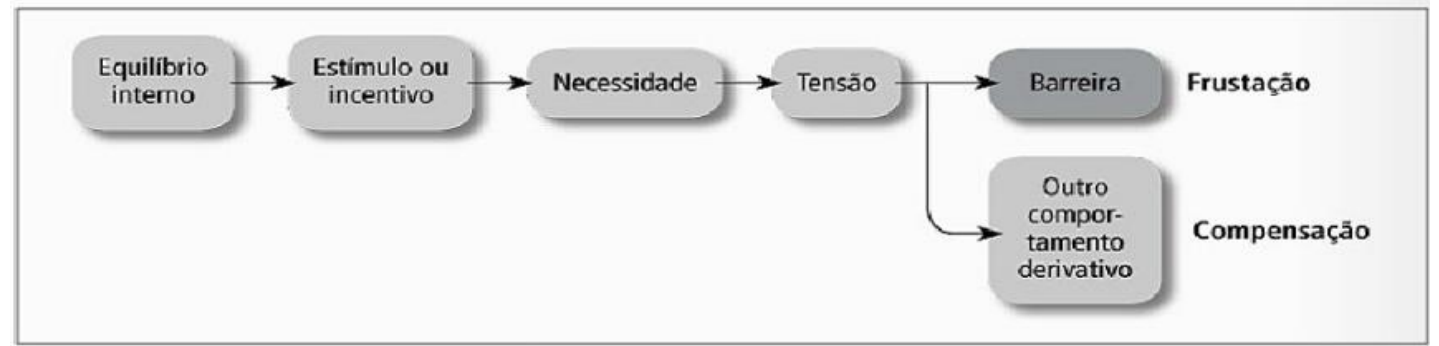

Fonte: Chiavenato (2009, p. 124).

Quando uma necessidade é satisfeita, o indivíduo passa por um período de equilíbrio, até que surja um novo motivo ou necessidade para então iniciar outro ciclo.

\section{Interferência da Motivação no Ambiente de Trabalho}

Segundo Lopes (2009, p. 10), “a motivação para o trabalho é uma expressão que indica um estado psicológico de disposição e vontade de perseguir uma meta ou realizar uma tarefa". É, pois, o entusiasmo e a vontade de desenvolver as atividades laborais de forma satisfatória, o que proporciona um sentimento prazeroso.

Para Bergamini (2002, p. 66), "o trabalho tem a propriedade de oferecer parâmetros para as expectativas e ideais de cada ser humano". Conhecer esses parâmetros torna-se imprescindível quando se pretende obter êxito nas metas ou objetivos traçados. Então, para que o indivíduo possa discernir entre interferências positivas ou negativas, é preciso que o trabalho a ser desenvolvido faça sentido para ele.

À proporção que a motivação para o trabalho é encontrada, surge a possibilidade de conhecer quais razões são positivas ou negativas no ambiente de trabalho. Certamente as interferências positivas vão incentivar o indivíduo a atingir suas metas e seus objetivos. No momento em que as necessidades são satisfeitas, ele buscará encontrar caminhos para lidar, da melhor forma possível, com os obstáculos. As interferências negativas geralmente são perniciosas, entretanto podem ser revertidas em benefício daqueles indivíduos aptos a gerenciar situações adversas.

\section{Metodologia}

O presente trabalho utilizou como base uma pesquisa bibliográfica de caráter descritivo e exploratório, em que se realizou um estudo de caso, por meio de questionário objetivo e estruturado. 
Segundo Gil (2008), a pesquisa bibliográfica é desenvolvida a partir de material anteriormente elaborado, constituído, sobretudo de livros e artigos científicos. O estudo de caso, a seu turno, constitui no estudo pormenorizado de um dado objeto, de modo a possibilitar seu detalhado conhecimento. Explorar o tema abordado de modo a promover maior familiaridade com o assunto, bem como descrever as características da amostra selecionada e os resultados obtidos apontam para uma pesquisa de caráter descritivo e exploratório.

Conforme os ensinamentos de Lakatos (2010), esta pesquisa se caracteriza como um estudo descritivo, uma vez que consiste em descobrir e observar motivações para o trabalho, com a finalidade de descrevê-las e interpretá-las, utilizando questionário objetivo e estruturado.

Para Severino (2007, p. 121), “o estudo de caso escolhido para a pesquisa deve ser significativo e bem representativo, de modo a ser apto a fundamentar uma generalização para situações análogas, autorizando inferências".

Sem dúvida, o estudo de caso sobre motivação é de suma importância para a pesquisa científica, pois, como já discutido antes, a motivação tem sido assunto recorrente nos ambientes de trabalho desde o início do século passado, tendo possibilitado o desenvolvimento de um grande número de pesquisas acerca do assunto.

\section{Lócus da Pesquisa e Análise dos Resultados}

Esta pesquisa foi realizada em uma Vara Federal localizada no município de Juazeiro do Norte - CE. A Vara foi inaugurada em 2005 e apresenta, em seu quadro de recursos humanos, 18 servidores. Para a realização desta pesquisa foi solicitada autorização do Magistrado daquela Instituição, que prontamente a concedeu. Os dados da pesquisa foram colhidos a partir de contatos, por meio de correio eletrônico, com os servidores daquela Vara Federal. Inicialmente, foram enviadas mensagens aos servidores, informando acerca da pesquisa bem como de sua importância, ocasião em que foi solicitado consentimento para sua realização. Após o consentimento, foram enviados e-mails aos servidores, em abril de 2014, quando thes foram realizadas perguntas sobre motivação no ambiente de trabalho. Para a realização da pesquisa foi utilizado questionário objetivo, que foi aplicado a 18 servidores da referida Vara Federal. A última resposta foi obtida em 30 de abril deste ano. Os dados obtidos foram consolidados em maio de 2014. 


\section{Análise dos Resultados}

Inicialmente, foi traçado o perfil dos servidores, levando em consideração: sexo, grau de escolaridade, tempo de serviço na instituição e idade. Posteriormente, foi realizado, através de questionário, estudo sobre os possíveis fatores capazes de impulsionar motivação.

Dos 18 (dezoito) servidores entrevistados, 08 (oito) são homens e 10 (dez) são mulheres, cuja percentagem corresponde a $44,44 \%$ para o sexo masculino e $55,56 \%$ para o sexo feminino.

A idade também foi levada em consideração para traçar o perfil dos servidores. Das informações obtidas, verificou-se que 03 (16,67\%) deles têm menos de 25 anos de idade; 11 (61,11\%) têm entre 25 e 35 anos; 03 (16,67\%) têm acima de 35 até 45 anos; e apenas 01 (5,55\%) servidor possui mais de 45 e menos de 55 anos.

Para melhor identificar o perfil dos servidores daquela Vara Federal, foi observado, ainda, o grau de escolaridade. Os dados mostraram um percentual de 44,45\% de servidores com nível superior, 33,33\% com pós-graduação e 22,22\% apenas com nível médio.

Dessa análise percebe-se que a grande maioria dos servidores $(77,78 \%)$ cursou uma graduação. Verifica-se, ainda, que nenhum dos servidores possui mestrado ou doutorado.

Outro fator observado foi o tempo de serviço na instituição, uma vez que nos primeiros anos de serviço, fenômenos como estágio probatório, períodos de avaliação e estabilidade, ainda não conquistados, podem interferir, ainda que de forma indireta, na motivação. Os dados obtidos constataram que 55,56\% dos trabalhadores têm até 02 anos de serviço, portanto sem estabilidade; 16,67\% trabalham há mais de 02 anos e menos que 05 anos; 22,22\% já trabalham há mais de 05 anos, mas não ultrapassando os 10 anos; e, por fim, 5,55\% trabalham há mais de 10 anos.

A representação gráfica a seguir mostra o grau de motivação, quando da possibilidade de envolvimento dos colaboradores no planejamento estratégico da Instituição.

Gráfico 01: Participação efetiva no planejamento estratégico da Instituição.

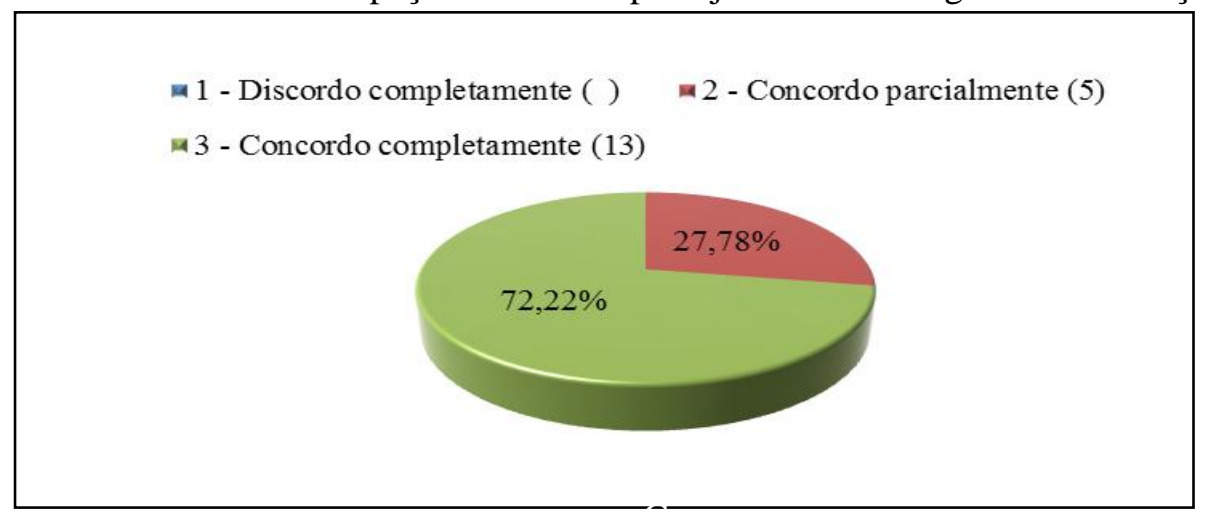

Fonte: Dados da pesquisa (2014). 
Os colaboradores foram questionados se a participação no planejamento estratégico da instituição gera motivação. $72,22 \%$ responderam que concordam completamente que participar de modo efetivo do planejamento é causa de motivação, enquanto os outros $27,78 \%$ concordaram de forma parcial com tal questionamento. Esse resultado demonstra um número bem maior daqueles que acreditam completamente na importância de participar do planejamento da Instituição. Trata-se, pois, de um fator positivo, capaz de gerar motivação para a vida profissional. Para Cavalcanti et al. (2009), o funcionário quando envolvido no planejamento da instituição apresenta-se mais comprometido. Acrescenta, ainda, que o planejamento desde que seguido de forma criteriosa é capaz de atingir seu intento.

O gráfico a seguir demonstra as informações a respeito da opinião dos colaboradores sobre a relação entre o volume de tarefas atribuídas e a motivação.

Gráfico 02: Elevado volume de tarefas.

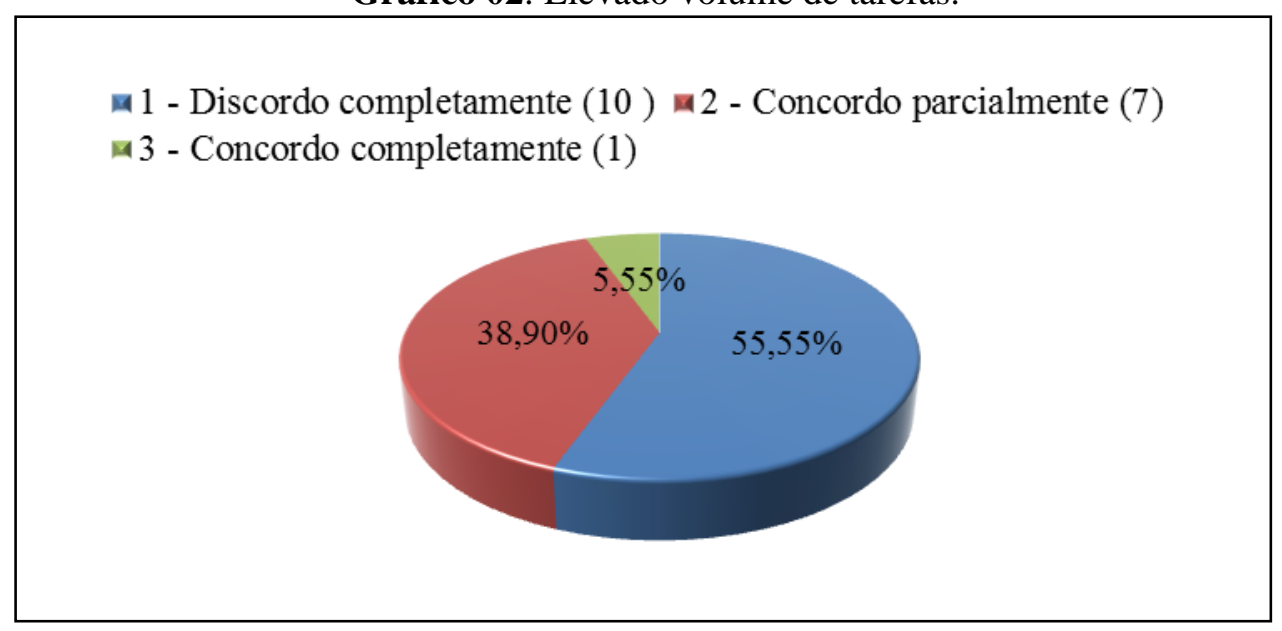

Fonte: Dados da pesquisa (2014).

De acordo com as respostas dadas a este quesito, receber um número elevado de tarefas não é fator de motivação, pois apenas 5,55\% deles concordam plenamente que se sentem motivados ao receber um elevado número de tarefas, enquanto 55,55\% discordam plenamente e 38,90\% concordam parcialmente. Para Cavalcanti et al. (2009), as metas devem ser aceitáveis e coerentes para o colaborador, devendo ser mensuráveis e quantificáveis.

Em seguida, buscou-se investigar a satisfação dos servidores acerca da autonomia no desempenho das funções, com o objetivo identificar a percepção dos servidores em relação a este assunto, utilizando a conexão das variáveis satisfação e autonomia. A resposta revelou uma relação direta para os servidores pesquisados, ou seja, quanto maior a autonomia percebida, maior a motivação em desenvolver as atividades. Segue o gráfico: 
Gráfico 03: Autonomia nas tarefas.

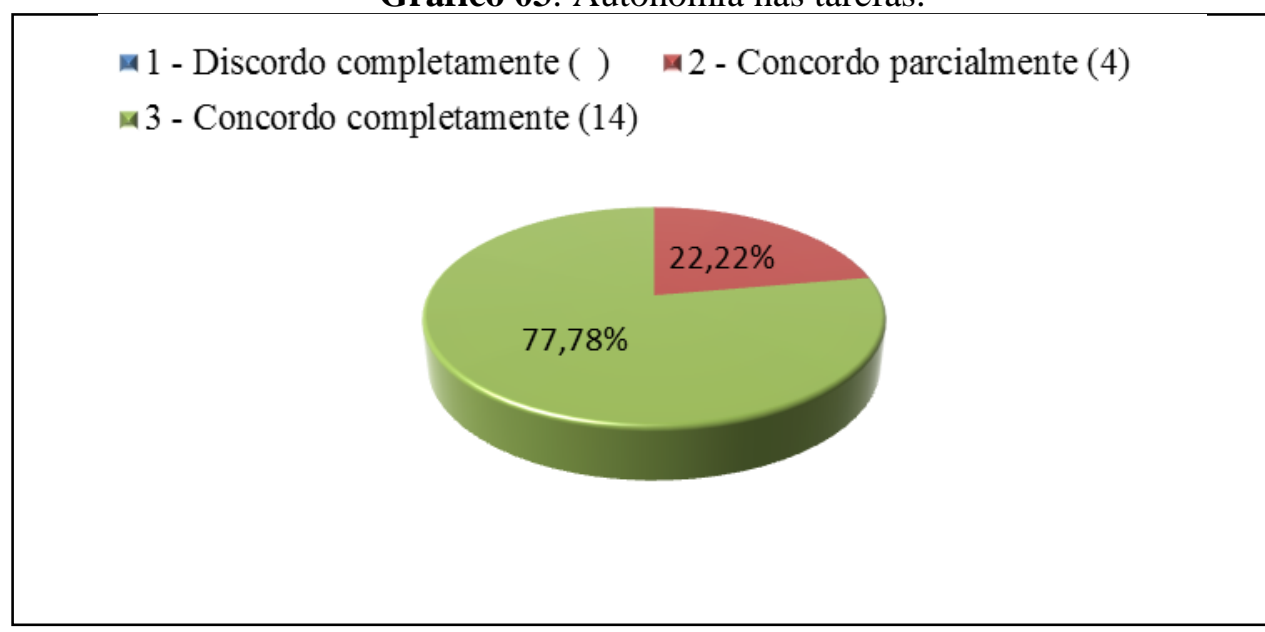

Fonte: Dados da pesquisa (2014).

Sobre motivação ao exercer as tarefas com autonomia, 77,778\% dos colaboradores disseram que a autonomia para desenvolver os trabalhos é fator de motivação, enquanto 22,222\% concordaram parcialmente. Para Cavalcanti et al. (2009), a autonomia aumenta a capacidade de desempenho e a motivação para contribuir com a instituição.

O gráfico a seguir demonstra os fatores capazes de promover motivação no que concerne ao estabelecimento de metas no ambiente de trabalho.

Gráfico 04: Participação da elaboração de metas.

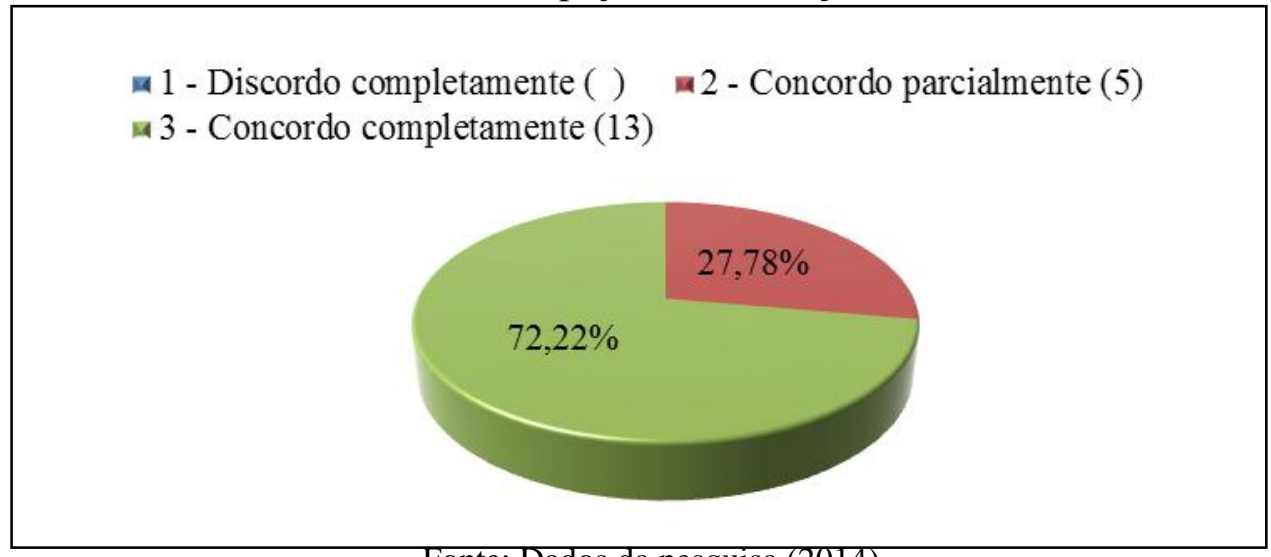

Fonte: Dados da pesquisa (2014).

Entre os 18 servidores que responderam ao questionário, 72,22\% concordaram plenamente que é fator de motivação participar da elaboração das metas, enquanto apenas $22,78 \%$ concordaram de forma parcial. Para Cavalcanti et al. (2009), envolver o funcionário de forma que este participe da elaboração de metas implica possibilitar maior comprometimento do colaborador, gerando motivação. 
A demonstração gráfica a seguir mostra o resultado, no campo da motivação, acerca da importância de cumprir as metas estabelecidas.

Gráfico 05: Cumprimento das metas estabelecidas.

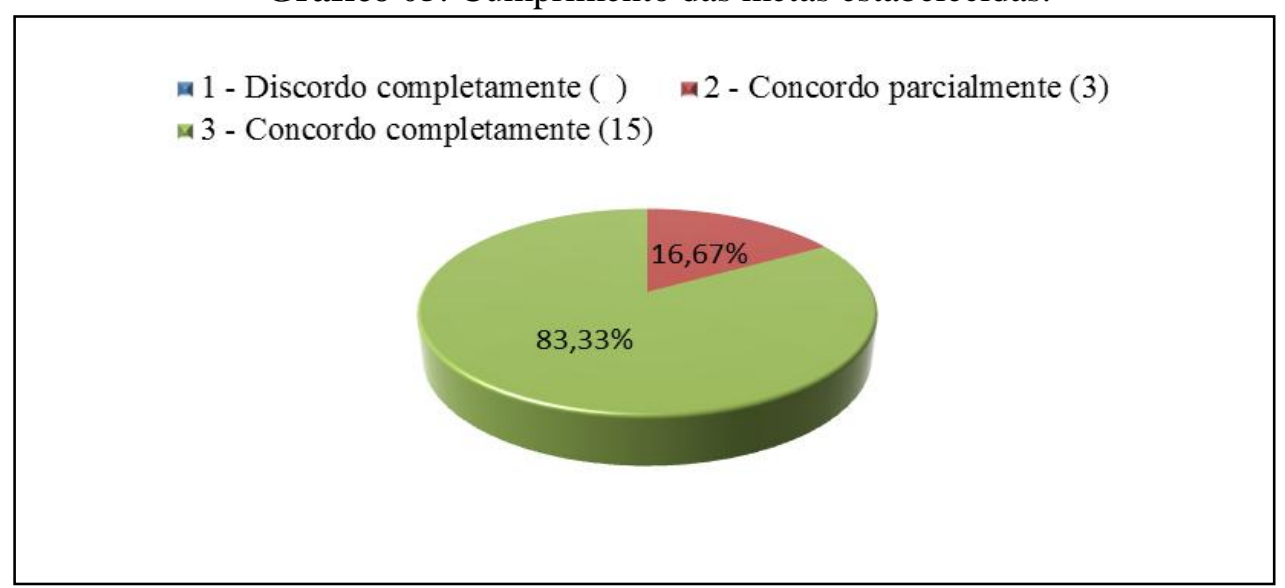

Fonte: Dados da pesquisa (2014).

Dos 18 servidores questionados, $15(83,33 \%)$ concordaram plenamente que cumprir metas estabelecidas gera motivação, enquanto $03(16,67 \%)$ colaboradores concordaram parcialmente com este questionamento. Segundo Murphy (2012), metas sinceras, necessárias e difíceis constituem desafios, e ao serem cumpridas proporcionam motivação e disciplina.

No que diz respeito a estabelecer uma rotina de trabalho, os dados podem ser visualizados no gráfico abaixo.

Gráfico 06: Rotina de Trabalho.

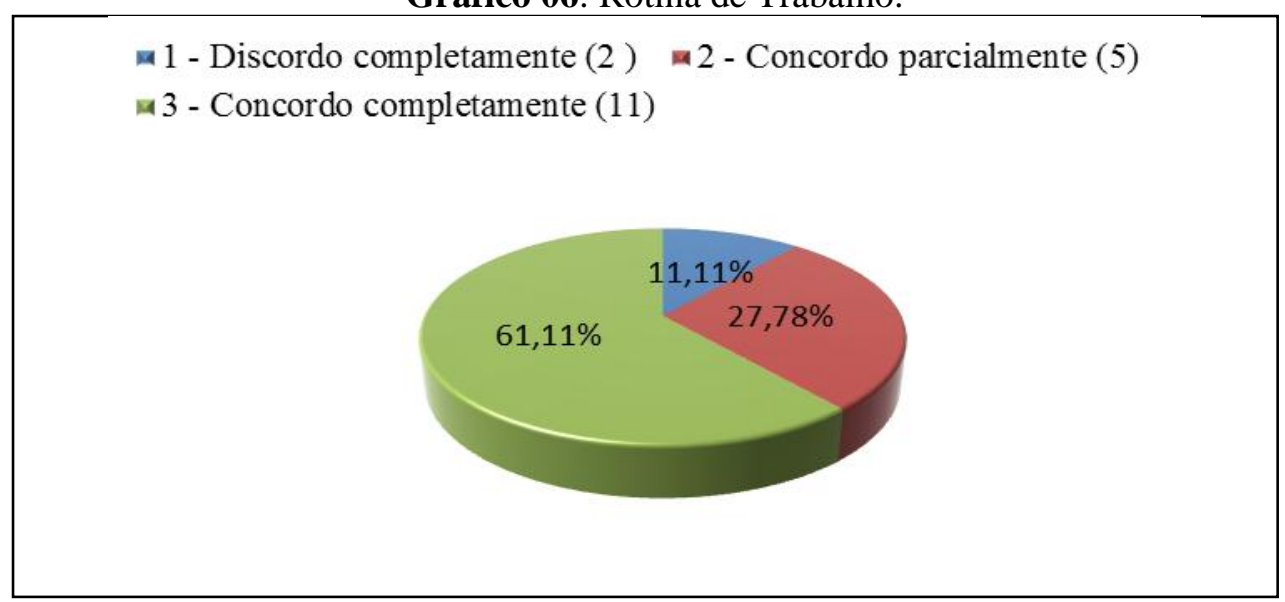

Fonte: Dados da pesquisa (2014).

Observa-se que a maioria $(61,11 \%)$ concorda completamente que estabelecer uma rotina de trabalho gera motivação, enquanto $27,78 \%$ concordaram de forma parcial, e apenas $11,11 \%$ discordaram plenamente desse questionamento. 
O gráfico a seguir mostra os dados relacionados à execução de tarefas desafiadoras e não rotineiras como fator motivacional.

Gráfico 07: Tarefas desafiadoras e não rotineiras.

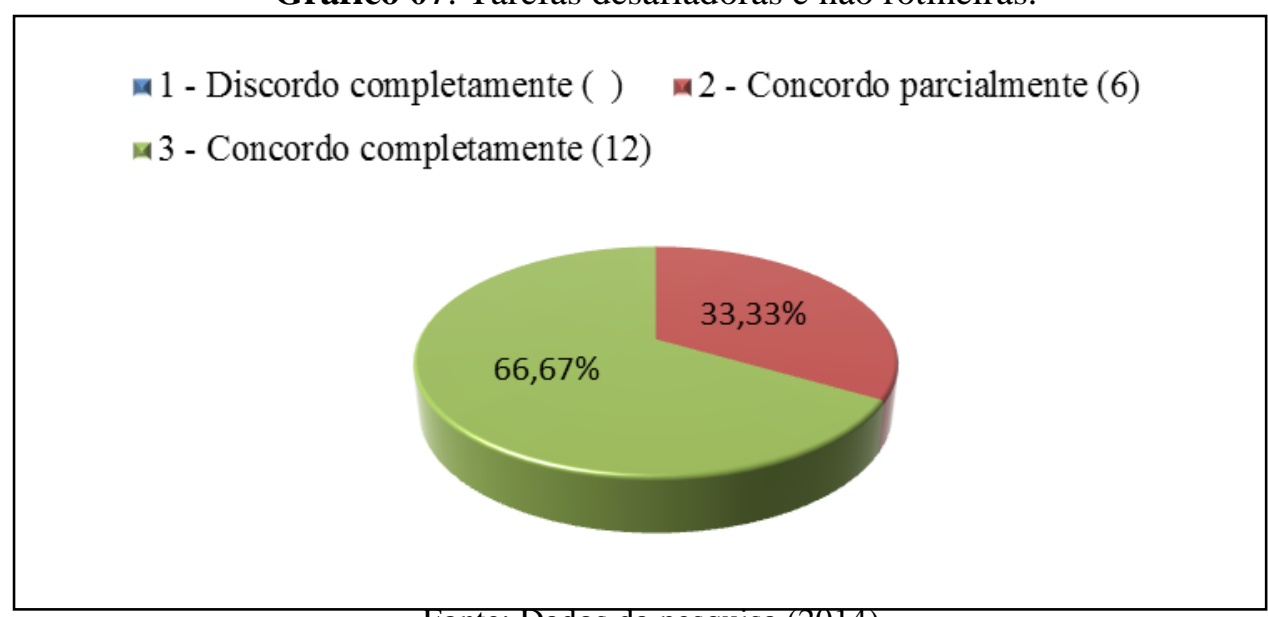

Fonte: Dados da pesquisa (2014).

A maioria $(66,67 \%)$ registrou que concorda completamente que receber tarefas desafiadoras e não rotineiras consiste em causa de motivação, ao passo que 33,33\% afirmaram que concordam de forma parcial. Para Chiavenato (2009), tarefas desafiadoras consistem em fator motivacional. Elas estão diretamente relacionadas ao progresso e crescimento dos colaboradores no ambiente de trabalho, podendo ser classificadas como fatores que satisfazem.

A representação gráfica a seguir mostra os dados a respeito do feedback recebido pelos funcionários acerca do trabalho desempenhado.

Gráfico 08: Feedback positivo acerca do trabalho desempenhado.

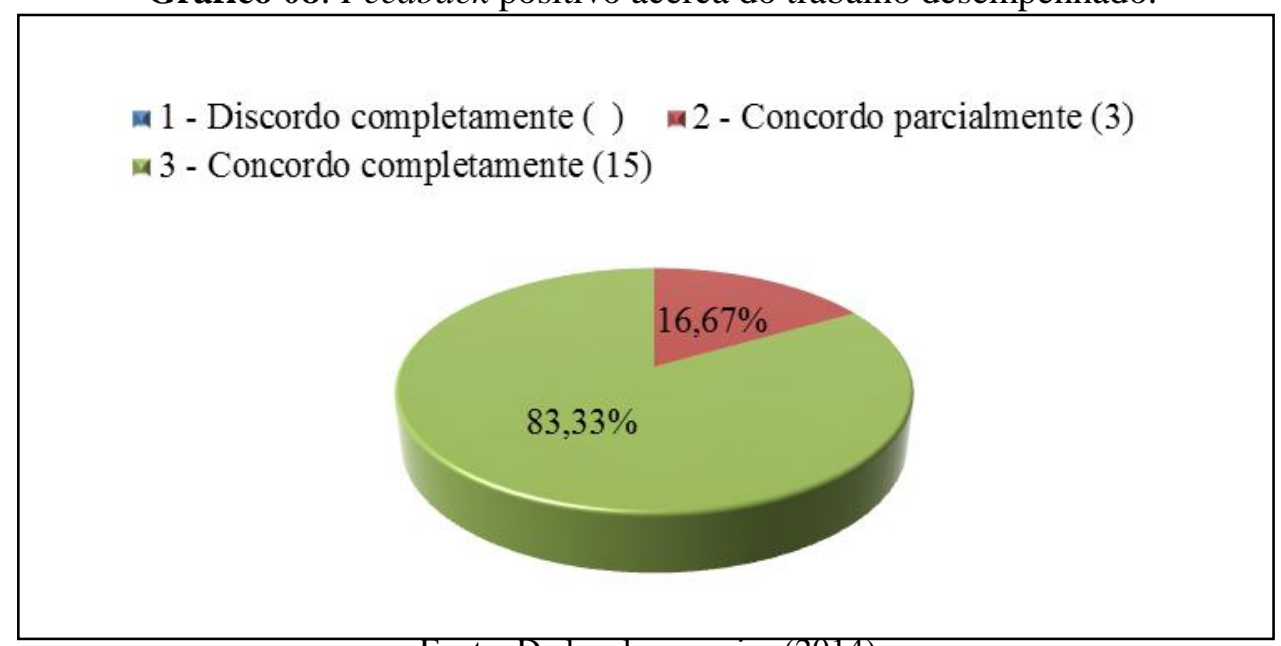

Fonte: Dados da pesquisa (2014). 
No que concerne a receber feedback positivo acerca do trabalho desempenhado, 83,33\% dos colaboradores disseram concordar completamente que receber feedback positivo tem efeito motivador, o que leva as pessoas a fazerem seu trabalho de forma satisfatória, enquanto que apenas 16,67\% declararam concordar apenas parcialmente que receber feedback positivo gera motivação.

De acordo com o assunto, ressalta-se:

O termo "motivação" envolve sentimentos de realização, de crescimento e de reconhecimento profissional por meio do exercício das tarefas e atividades que oferecem suficientes desafios e significado para o trabalhador (CHIAVENATO, 2009, p. 130).

Feedback positivo é fator motivacional, pois se trata de reconhecer o esforço do trabalhador em relação às suas funções, o que proporciona ao colaborador o sentimento de realização.

A questão representada graficamente a seguir foi formulada para saber a opinião dos colaboradores sobre o reconhecimento do trabalho desempenhado como fator motivacional.

Gráfico 09: Reconhecimento do trabalho.

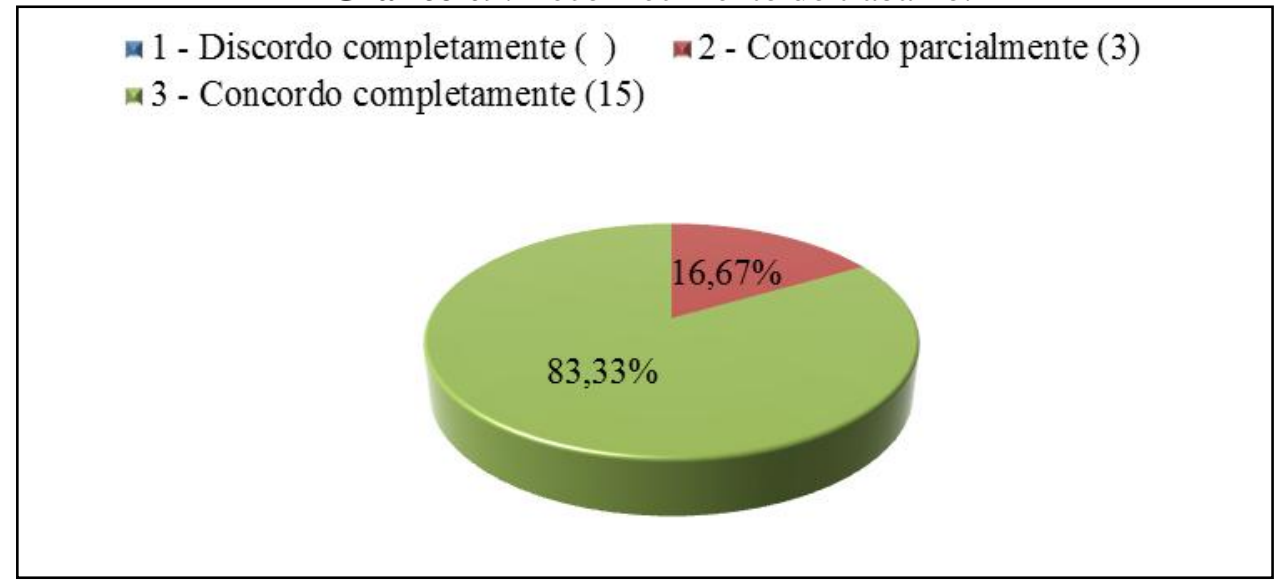

Fonte: Dados da pesquisa (2014).

Entre os 18 servidores, $15(83,33 \%)$ deles concordaram completamente que o reconhecimento do trabalho é fator motivacional enquanto $16,67 \%$ concordaram parcialmente que ter o trabalho reconhecido é motivador. Trata-se de um fator motivacional no entendimento de Herzberg e de uma necessidade do ego (estima) para Maslow (CHIAVENATO, 2009).

O gráfico abaixo mostra a opinião dos colaboradores em relação à compensação financeira pelo trabalho desempenhado. 
Gráfico 10: Recompensa financeira.

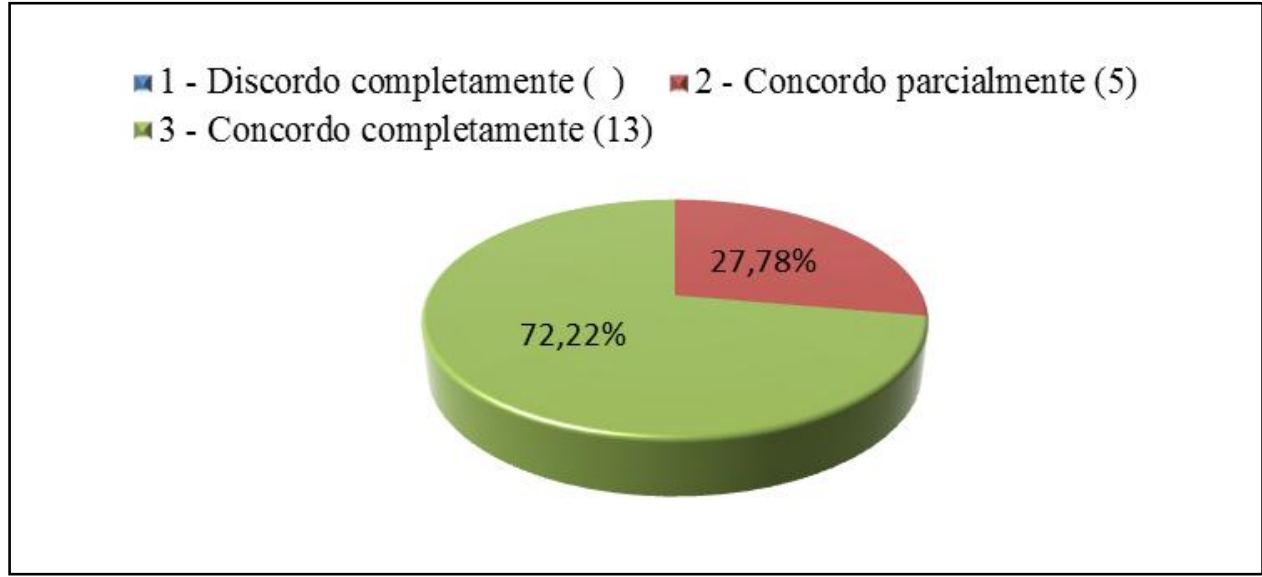

Fonte: Dados da pesquisa (2014).

Observa-se que $72,22 \%$ concordaram completamente que a recompensa financeira pelo trabalho desempenhado é importante para motivação dos servidores, enquanto $27,78 \%$ concordaram parcialmente com este questionamento. Segundo Bowditch e Buono apud Cavalcanti et al. (2009), a recompensa só gera motivação quando o indivíduo valoriza essa recompensa, quando ele acredita que seu esforço implicará em melhor desempenho e consequentemente em maiores recompensas.

O gráfico a seguir mostra a opinião dos colaboradores no que se refere à comunicação com gestores e demais servidores.

Gráfico 11: Comunicação com gestores e demais servidores.

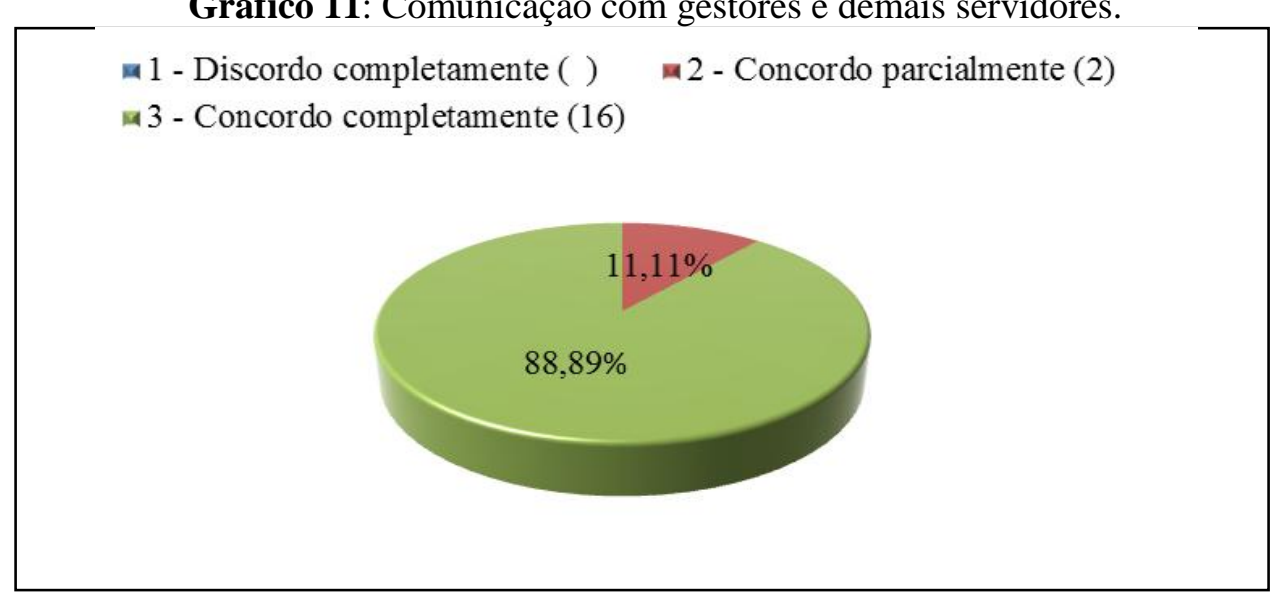

Fonte: Dados da pesquisa (2014).

Dos 18 colaboradores questionados sobre estabelecer uma boa comunicação com os gestores e demais servidores, 16 deles responderam concordar completamente com a importância de uma boa comunicação com servidores e gestores, o que significa que $88,89 \%$ deles entendem que a comunicação com gestores e demais servidores constitui fator motivacional, enquanto somente $11,11 \%$ concordaram em parte que essa comunicação é importante para motivação no ambiente de 
trabalho. Analogamente às teorias motivacionais abordadas, esse resultado aponta para um perfil de colaboradores predominantemente voltado para as necessidades de afiliação identificadas por McClelland (CAVALCANTI et al., 2009); para as necessidades sociais descritas por Maslow e para as relações interpessoais descritas por Herzberg. (CHIAVENATO, 2009).

Os dados a seguir, representados em gráfico, mostram a resposta dos colaboradores quando perguntados sobre cooperação entre colegas no ambiente de trabalho.

Gráfico12: Relação de cooperação.

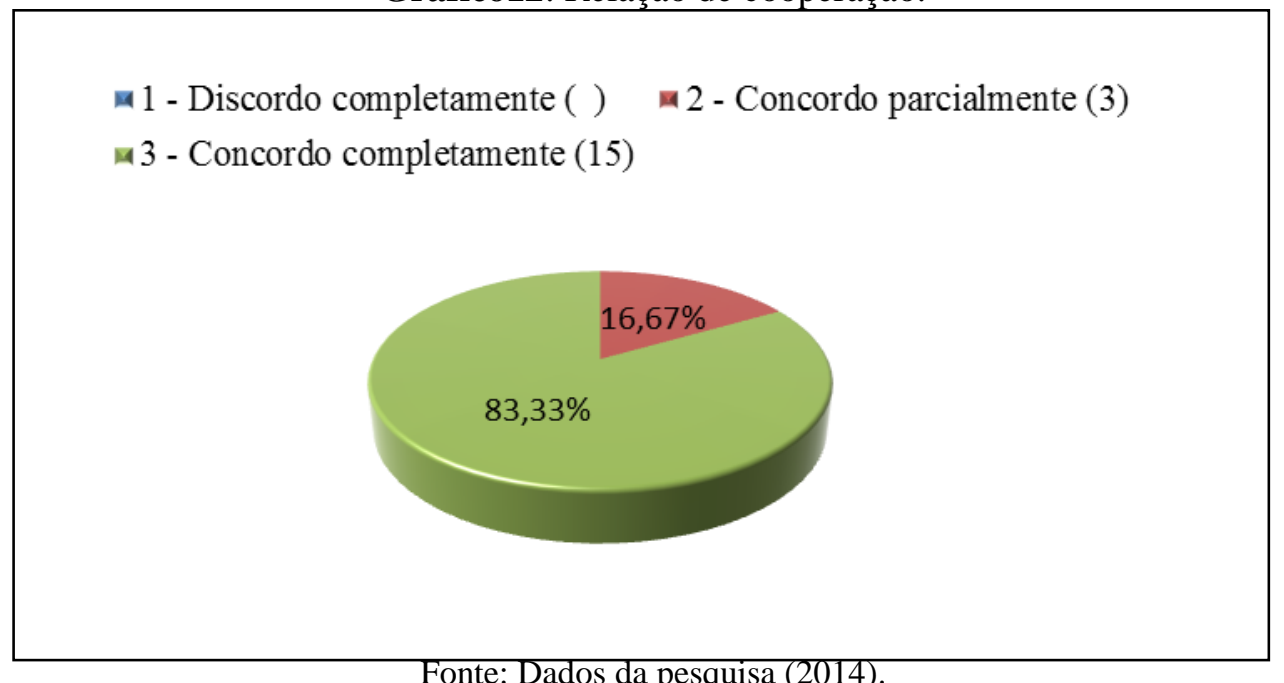

A percentagem de colaboradores que disseram concordar completamente que é fator motivacional a cooperação entre colegas de trabalho é de $83,33 \%$, um número muito superior aos que apenas concordam parcialmente, cuja percentagem é de 16,67\%. Isso demonstra que num ambiente de trabalho onde as pessoas se ajudam, o trabalho se torna menos árduo e possibilita um fator positivo na motivação. Para McClelland, "pessoas com motivação para afiliação trabalham melhor quando elogiadas por atitudes de cooperação" (CAVALCANTI et al., 2009, p. 93).

A seguir está descrita no gráfico a porcentagem para a questão: participo de capacitações com o intuito de aprimorar o relacionamento cidadão-usuário da Justiça Federal. 
Gráfico 13: Participação de capacitação.

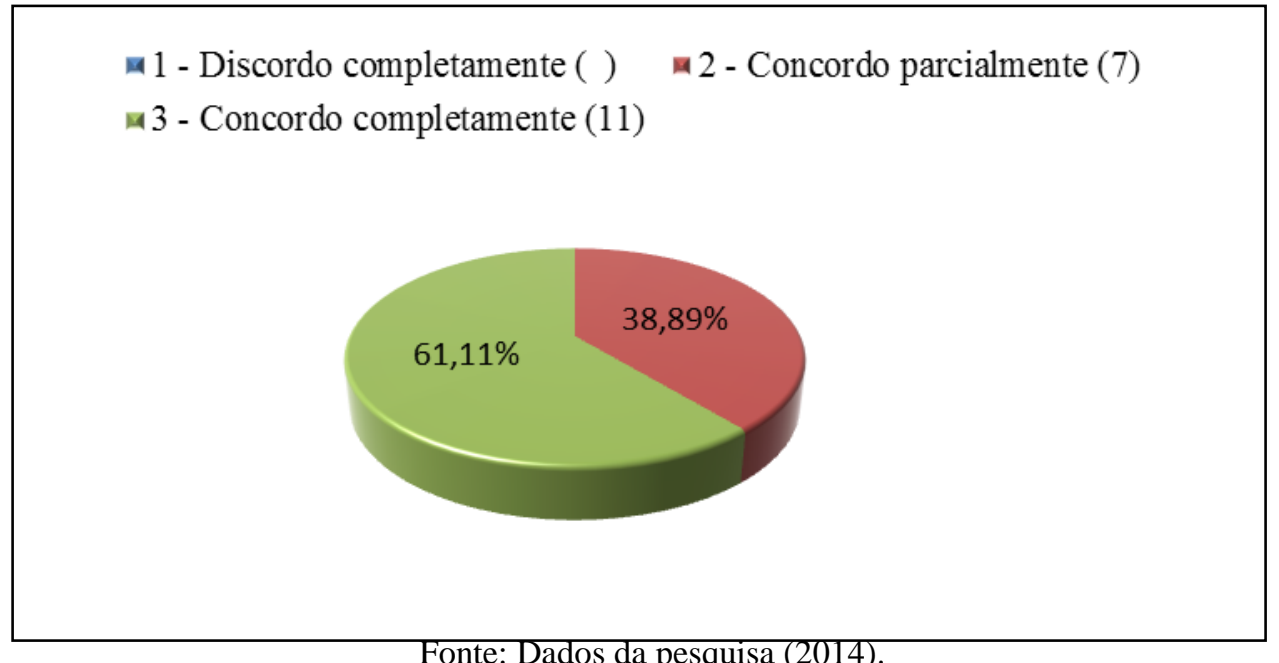

Fonte: Dados da pesquisa (2014).

Entre 18 colaboradores questionados, 11 disseram concordar plenamente que é importante para a motivação participar de capacitações com o intuito de aprimorar o relacionamento com os que buscam a justiça, o que totalizou $61,11 \%$. Os outros $38,89 \%$ disseram concordar de forma parcial que tais capacitações geram motivação. Para Cavalcanti et al. (2009), a preocupação com a necessidade de segurança, identificada por Maslow, pode levar o colaborador a participar de curso de pós-graduação com o intuito de contribuir para a organização e de proporcionar maior segurança no trabalho.

\section{Considerações Finais}

O tema motivação remete a uma criteriosa discussão, notadamente na área de gestão de pessoas. Assim, para que as instituições desenvolvam um bom trabalho é preciso, sobretudo, conhecer os fatores que motivam seus colaboradores.

A partir dos resultados obtidos neste trabalho, foi identificado que mais da metade dos colaboradores pesquisados são do sexo feminino, apresentando idade entre 25 e 35 anos, com nível superior de escolaridade e com menos de dois anos de serviço na instituição.

Com base nos dados coletados, observa-se que estabelecer uma boa comunicação com gestores e demais servidores é considerado o principal fator motivacional para os colaboradores daquela Vara Federal, já que obteve o maior percentual de concordância $(88,89 \%)$. Analogamente à teoria das necessidades socialmente adquiridas, o referido percentual aponta para um perfil de colaboradores predominantemente voltado para necessidades de afiliação, que são necessidades, segundo MsClelland, voltadas para a valorização da comunicação e do trabalho entre amigos. 
Analisando detidamente os resultados, foi verificado que o cumprimento de metas estabelecidas pela Instituição, a existência de feedback positivo acerca do trabalho desempenhado, a relação de cooperação e o reconhecimento do trabalho desenvolvido constituem importantes fatores de motivação para 83,33\% dos colaboradores. Esses resultados demonstram a importância de se contemplar, em especial, os fatores apontados pela maioria dos servidores ora questionados para o êxito da instituição.

Sobre atitudes que ajudam a motivar esses colaboradores, podem ser citadas práticas como: boa comunicação; elogio; reconhecimento; além de atribuição de tarefas passíveis de compreensão e execução, com vistas à motivação e à satisfação no ambiente de trabalho.

Estar atento às novas competências e reconhecer que muitas práticas, até hoje aplicadas, precisam ser substituídas é fator preponderante para que as instituições sejam bem sucedidas. Oferecer condições satisfatórias para o desenvolvimento das atividades de forma salutar é indispensável na engenhosa tarefa de gerenciar pessoas, num mundo cada vez mais competitivo e globalizado.

Cumpre registrar que a motivação se desenvolve melhor em um ambiente de trabalho onde o colaborador é valorizado e recompensado ou, ainda, quando este participa das decisões, assumindo o papel de sujeito ativo no processo de crescimento da organização.

Resta claro, portanto, que a motivação está intimamente ligada a fatores intrínsecos, relacionados diretamente aos próprios anseios individuais. Desse modo, conhecer tais fatores contribui de forma inequívoca para possibilitar às organizações novas práticas de gestão, capazes de motivar seus colaboradores com vistas a uma administração pautada pela excelência em gestão de pessoas.

\section{Referências}

BERGAMINI, Cecília Whitaker. Motivação: uma viagem ao Centro do Conceito. Revista Rae, 64, VOL.1, No2, NOV 2002 A JAN 2003, p. 63-67 - FGV, São Paulo -SP. 2002.

CAVALCANTI, Vera Lúcia. CARPILOVSKY, Marcelo. LUND, Myriam. LAGO, Regina Arczynska. Liderança e motivação. - $3^{\text {a }}$ edição - Rio de Janeiro: Editora FGV, 2009.

CHIAVENATO, Idalberto. Administração de Recursos Humanos: Fundamentos Básicos. $-7^{\mathrm{a}}$ edição Rev. Atual. - Barueri, São Paulo, 2009.

GIL, Antonio Carlos. Como elaborar projetos de pesquisa. $4^{\text {a }}$ edição - São Paulo: Atlas, 2008.

KWASNICKA, Eunice Lacava. Introdução à Administração. 6 $6^{a}$ edição - São Paulo: Atlas, 2009.

LAKATOS, Eva Maria. MARCONI, Marina de Andrade. Fundamentos da Metodologia Científica. $7^{\mathrm{a}}$ edição - São Paulo: Atlas, 2010. 
LOPES, Gabriela Alvarenga Colmenero. Motivação no Trabalho. 2003. 45 Folhas. Pós-Graduação Latu Senso (Monografia), Projeto A Vez do Mestre. Universidade Cândido Mendes Rio de Janeiro. Disponível em <http://www.avm.edu.br/monopdf/23/GABRIELA\%20ALVARENGA\%20COLMENERO\%20LOPE S.pdf $>$. Acesso em 30 de junho de 2014.

MARRAS, Jean Pierre. Administração de Recursos Humanos do operacional ao estratégico. - $14^{\text {a }}$ edição - São Paulo: Saraiva, 2011.

MURPHY, Mark. Metas que desafiam: a ciência dos feitos extraordinários; tradução: Henrique Monteiro. - São Paulo: Clio Editora, 2012.

RIBEIRO, Antônio de Lima. Gestão de pessoas. - $1^{\mathrm{a}}$ edição - São Paulo: Saraiva, 2006.

SEVERINO, Antônio Joaquim. Metodologia do Trabalho Científico. $23^{\text {a }}$ edição - São Paulo: Cortez, 2007.

VERGARA, Sylvia Constant. Gestão de pessoas. - $6^{\text {a }}$ edição - São Paulo: Editora Atlas S.A., 2007.

WHITMORE, John. Coaching para aprimorar o desempenho: os princípios e a prática do coaching e da liderança; tradução: Henrique Monteiro. - São Paulo: Clio editora, 2012.

\section{Como citar esse artigo (ABNT):}

BARBOSA, Francisca V.F.; ALMEIDA NETO, José Leandro. O Perfil Motivacional dos Colaboradores de uma Vara Federal do Município de Juazeiro do Norte - CE. Id on Line Revista de Psicologia, Julho de 2014, vol.8, n.23, p. 152-170. ISSN 1981-1179. 